\title{
o conhecimento e a construção do novo cosmos social
}

\author{
Knowledge and the construction of the new social cosmos
}

Vivaldo Luiz CONTI ${ }^{1}$

R E S U M O

A B S T R A C T

O maior risco para os habitantes do nosso tempo ao viver em um mundo fragmentado, onde as porções não se juntam, é o de desenvolver (ainda mais) a indiferença e o alheamento para com os outros, para aquilo que o cerca, encerrando-se em uma espécie de autismo. Tentando apontar os modos pelos quais o todo poderia ser recomposto, este artigo chama a atenção para os meandros de uma criação humana especial, a ciência. Outrossim, enfatiza a necessidade da reconstrução de teorias unificadoras e totalizadoras de mundo, como a única forma de o homem conseguir estabelecer um grau de entendimento que lhe permita conviver harmoniosamente com a natureza e consigo mesmo.

Palavras-chave: moderno, pós-moderno, ciência, informação, conhecimento.

The greatest risk for the inhabitants of our time, living in a fragmented world where togetherness does not exist, is to develop (even further) the indifference and the alienation towards other people, things, and surroundings, enclosing themselves in a type of autism. Trying to indicate how to rebuild the whole, this article draws attention to the meanders of one of the human creations, Science. It also emphasizes the need to rebuild unifying and totaling theories as the only way humans will manage to establish a degree of understanding that may allow them to live harmoniously with nature and themselves.

Key words: modern, postmodern, science, information, knowledge.

\footnotetext{
${ }^{1}$ Diretor Adjunto de Disseminação de Informação da Fundação Seade. Avenida Casper Lúbero, 464, 30 Andar, 01033-000, São Paulo, SP, Brasil. E-mail: <vlucontiliseade.gov.br>.

Recebido e aceito para publicação em 20/9/2004.
} 


\section{NASCIMENTO E MORTE DO $M O D E R$ N O}

Até meados do século XIX a ciência tinha bem delimitado o campo de ação de suas diversas disciplinas. As pesquisas eram conduzidas na direção vertical, isto é, estavam voltadas para o aprofundamento do conhecimento dentro das especialidades. O determinismo de Newton era a base do pensamento científico que, por sua vez, induzia os indivíduos a criarem uma visão de mundo estável e apontava para uma direção unívoca, com papéis e posições definidas e pouco cambiáveis. Nos primórdios do século seguinte essa ordem das coisas já estava definitivamente abalada por uma série de novas teorias, como a da relatividade de Einstein, a da física quântica e a da incerteza proposta por Boltzmann e Gibbs. Nada mais é absoluto e sobre qualquer certeza recai agora a suspeita. $O$ universo torna-se contingente (MOTOYAMA, 1977). As indagações suscitadas pelas novas teorias vão encontrar um ambiente fértil, nos primeiros cinqüenta anos do século $\mathrm{XX}$, para a busca de respostas por meio da expansão das pesquisas científicas impulsionada pelos dois conflitos mundiais (especialmente o segundo) e, logo após, pela guerra fria.

Nesse mesmo espaço de tempo de cinco ou seis décadas, em que a ciência expande-se e ramifica-se, a modernidade atinge seu auge, após um período de mais de cento e cinqüenta anos de gestação, contados desde o instante de sua fecundação pelas idéias do iluminismo. Para escapar das agruras do momento, a tradição recomendava olhar para o passado e propunha sua reprodução idealizada no presente. O passado era o paraíso perdido que o homem, por seus desvios de conduta, havia deixado fenecer. O mundo perfeito estava nos tempos idos, de onde, em uma versão glamourosa, haviam sido devida e previamente expurgadas quaisquer injustiças ou violências. As relações sociais privilegiadas eram aquelas que vigiam antes da revolução Industrial, baseadas, portanto, no mundo da economia agrícola. Conseqüentemente, o universo rural era o protagonista da tradição.

O moderno rompe com tudo isso. Começa afirmando o direito do indivíduo à emancipação e confere-lhe para isso a liberdade formal. Para superar as intoleráveis imperfeições do presente, propõe o futuro, quando se chegará à sociedade ideal modificada e ajustada pela ciência e a tecnologia. Pregava que o passado era sinônimo do atraso e da manutenção de velhas formas de dominação. Tomava como modelo do novo, o urbano, onde grandes transformações podiam ser vistas em curto espaço de tempo. A força de seu discurso era sustentada pelas invenções (eletricidade, telefone, carro, aeroplano, etc.), que a olhos vistos estavam modificando (e prometendo modificar ainda mais profundamente) o mundo e as relações sociais. Como argumento de sedução adicional, o moderno ponderava que, mesmo a mudança não sendo rápida o bastante para melhorar a vida dos contemporâneos, certamente as gerações futuras, seus próprios filhos e netos veriam um mundo novo, muito superior ao atual.

As origens do moderno repousam no iluminismo que, para Hegel, partia de "algo que não somos, mas deveríamos ser" (HABERMAS, 1998, p.36). Ao recusar aceitar o ser humano como ele é, projetar um modelo idealizado desse ente e apontar um caminho (a educação) para atingi-lo num tempo à frente, o iluminismo rompe com o conformismo, sepulta qualquer possibilidade de que as coisas permaneçam como estão e alia-se com a ambição, com o desejo irrefreável de mudar o estado das artes. Vindo de outra direção e com objetivos menos nobres, o capitalismo, desde seus primórdios, somou-se ao iluminismo no impulso transformador, ao alterar radicalmente as relações entre os indivíduos e as condições materiais da sociedade, pelo estabelecimento de um novo modo de produção. É o capitalismo que vai dar a marca registrada da modernidade, a sofreguidão pelo 
novo, visto agora como sempre melhor que o antigo, irrompendo em uma paixão avassaladora pelo futuro, daí em diante um objeto de desejo ansiosamente esperado.

$\mathrm{Na}$ modernidade assiste-se também a emergência da quarta dimensão. Somente aí o tempo vai adquirir uma nova conotação e, com ela, relevância para ser alçado à condição de igualdade com as outras três. Na tradição, o mundo deslocava-se dentro de um ciclo, no qual tudo se repetia eternamente, onde o futuro reproduziria o passado. Qualquer rompimento nessa sucessão de acontecimentos era considerado uma anomalia que deveria ser corrigida, para que as coisas voltassem ao seu eixo. É a modernidade que vai agudizar a noção de tempo ao negar que o movimento do mundo ocorresse em ciclos fechados, voltados sobre si mesmos, apresentando-o, em contraposição, na forma de uma reta de extensão ignorada na direção do passado e infinita no sentido do futuro. É o tempo linear, onde a idéia do progresso torna incerto 0 destino do indivíduo, embora com vastas possibilidades de melhorar em relação ao presente. Nessa visão não há lugar para a rigidez, tudo se faz fortuito, contingente e fugaz. Antes absoluto, repetitivo, estagnado, o tempo converte-se em algo fluido, escorregadio, relativo (depende da posição do observador), o que passa e não volta. Agora, associa-se a ele a sensação da perda e, contra esta, manifesta-se a urgência, a necessidade de realizar, de fazer acontecer em determinado lapso de tempo.

O conceito de espaço também sofre mutações importantes. De um lado, ganha precisão e contornos exatos, com a prevalência das formas geométricas regulares. Tudo é meticulosamente dividido para aproveitar o máximo possível o espaço, fronteiras são rigorosamente demarcadas, distâncias são medidas com precisão. De outro, sua existência surge associada ao tempo, fundindo-se com este no conceito espaço/tempo, podendo inclusive curvar-se sob a força da gravidade. As constru- ções teóricas de Einstein não poderiam ter surgido em épocas anteriores. Também a ciência é produto de seu tempo.

Todavia, na segunda metade dos anos 40 do século $X X$, a ciência colecionava relativismos e incertezas. Várias evidências apontavam também que havia "algo de podre no reino da Dinamarca", que o mundo dos sonhos prometido pela ciência e tecnologia parecia não só cada vez mais distante de concretizar-se, como ameaçava virar um pesadelo. Contudo, o discurso moderno não absorvia nada disso. Pelo contrário, uma de suas principais características era a confiança crescente e quase ilimitada na ciência como chave para resolver os problemas e imperfeições do mundo. Os governos, quer fossem capitalistas ou se declarassem socialistas, propagandeavam os avanços científicos, insistindo em mostrar e projetar as conseqüências que eles já tinham e as que provocariam na vida das pessoas, agora ou em período mais ou menos breve, procurando passar aos cidadãos a sensação de que tudo caminhava para melhor, ou seja, a idéia do progresso como ininterrupto e positivo. O que parecia ser a força do moderno vai revelar-se, em pouco tempo, o seu calcanharde-aquiles.

A visão de um mundo paradisíaco no futuro, por intermédio do desenvolvimento contínuo e acelerado da ciência, sofre sucessivos abalos com os horrores das duas grandes guerras mundiais e as dantescas explosões de bombas atômicas sobre as cidades japonesas de Hiroshima e Nagasaki. O cálice da desconfiança vem a transbordar com a guerra fria e a corrida nuclear que ela desencadeia. A ameaça de uma hecatombe nuclear, que praticamente significaria o fim da civilização sobre a face da terra, escancarava definitivamente o lado perverso da ciência. Revelava, por exemplo, que a carnificina causada pelas armas de guerra, criadas e desenvolvidas com diligência pelos cientistas, não era um paradoxo, mas uma vertente da ciência, o outro lado da moeda. 
Quando a ciência era colocada a serviço de interesses escusos, de governos ou grupos econômicos, seus efeitos daninhos podiam sobrepujar ou anular os benefícios obtidos em outras aplicações. Mostrava também o uso da ciência submetido a uma vontade política que era mera expressão do poderio econômico e não do desejo coletivo da sociedade. Por tais razões, o discurso em que o mundo caminhava para o éden, conduzido pela mão firme do conhecimento científico, caiu sob forte e justificada suspeita. A classe governante já não conseguia esconder suas manobras destinadas a desviar a atenção do povo aos desatinos perpetrados por ela na corrida armamentista, seja contra o meio ambiente ou em outras áreas. Não menos grave, as visões totalizantes repetidamente desandaram em totalitarismos, esmagando a individualidade e calando muitas vozes e consciências por meio da repressão, da tortura e também através do dinheiro e da troca de favores. Não tardaria para que os espíritos mais lúcidos e indignados começassem a contestar e a denunciar esse estado de coisas. O moderno começava, merecidamente, a estilhaçar-se.

Em 1957 Jack Kerouac publica On the Road, onde despreza os empregos normais e prega a sobrevivência minimalista e a vida na estrada. Ao lado de Allen Ginsberg, torna-se o expoente da chamada "Geração Beatnik", a primeira manifestação cultural de larga influência que pregava a liberdade em contraposição aos papéis e posições sociais que o sistema procurava impor às pessoas. Em Stanford, Aldous Huxley falava do "milagre do desabrochar da existência" que percebera num vaso de rosas, depois de consumir mescalina. Em Eros e Civilização, Herbert Marcuse expunha a angústia do homem moderno resultante da repressão social imposta por uma sociedade mecanicamente competitiva., Em a Elite do Poder, Wright Mills mostrava o embuste da democracia americana dominada cada vez mais pelas corporações e pelo complexo industrial-militar (GASPARI, 2002).
Eram apenas alguns exemplos das idéias libertárias que fervilhavam nas universidades, na literatura, no cinema e na música fornecendo as bases teóricas, símbolos e palavras de ordem para a contestação de todo um sistema de vida.

Mais suscetíveis de serem influenciados, por encontrarem-se em fase de formação de suas personalidades, abertos para o mundo, os jovens abraçam essas idéias e passam a atuar cada vez com mais intensidade para mudar o status quo. Um furacão de protestos varre as principais nações do mundo. Trabalhadores, estudantes, minorias e também maiorias (as mulheres) insurgem-se contra o establishment. De movimentos quase beatíficos como o hippie, até a luta armada, o espectro da contestação abrange múltiplos campos e caminhos de ação. Combatia-se a desigualdade social, a discriminação das minorias, a opressão sobre as mulheres, a guerra, o lucro dos capitalistas, a ditadura soviética, tudo o que impedia a liberdade do homem de viver sua vida como desejasse. "A inexorabilidade da existência burguesa, a onisciência do poder e a invencibilidade do mais forte, certezas da década de 50 , tornam-se dúvidas no fim dos anos 60" (GASPARI, 2002, p.234).

Em maio de 1968 dez milhões de franceses, trabalhadores e estudantes entram em greve. Nas ruas de Paris erguem-se barricadas e os protestos se transformam em batalhas campais entre a polícia e manifestantes. A agitação espalha-se pelo mundo: Alemanha, Itália, Inglaterra e América do Sul. Nos EUA, às lutas dos negros contra a discriminação racial, juntamse as manifestações contra a guerra do Vietnã. Em janeiro de 1968 os guerrilheiros vietcongs realizam a ofensiva do Tet, desmoralizando a propaganda de guerra do governo americano, que dava o conflito como praticamente ganho, caminhando para o término. A União Soviética enfrentava na Checoslováquia, no episódio que ficou conhecido como a Primavera de Praga, uma série de reformas introduzidas por Alexander 
Dubcek, entre as quais a abolição da censura e maior liberdade de expressão, libertação de presos políticos e independência dos sindicatos frente ao Partido Comunista. A revolta estava no ápice, os dois establishments mostravam-se abalados. No ocidente, alguns governos aparentemente estavam a ponto de ruir, e não se afiguravam capazes de reunir forças para reverter a situação. Parecia o princípio do fim da ordem estabelecida.

Todavia faltava ao conjunto desses movimentos, além de uma coordenação geral, a clareza quanto aos meios de atingir seus objetivos e, talvez, mesmo o principal, a existência de um objetivo único, concreto. Após a confluência, por assim dizer acidental, de 1968 esses movimentos nunca mais entraram em sincronia. Alguns lograram avançar em muitos dos seus objetivos, outros conseguiram ver atendidas, pelo menos em parte, suas reivindicações e os demais foram derrotados, mas qualquer que fosse o desfecho chegou-se sempre ao mesmo resultado - uma progressiva desmobilização. Esse final não pode ser, é claro, desvinculado das estratégias de ambos os establishments (o capitalista e o soviético) ao lidar com todas essas questões. Desde a política integracionista praticada pelo governo americano em relação aos negros, a adoção de negociações que alternavam concessões e endurecimento, até a brutal invasão da Checoslováquia, os governos ocidentais e a União Soviética retomaram, aos poucos, o controle da situação e reverteram a seu favor a balança política. Não obstante tivessem alcançado a vitória, os governos encontraram-se diante de uma situação inteiramente nova, que havia mudado definitiva e irremediavelmente. Toda uma visão de mundo desaparecera ou estava se evaporando rapidamente e, com ela, ia-se também, o espírito do moderno.

O mundo moderno, embora em constantes e inúmeras violentas mutações, tinha uma lógica inerente e sua trajetória podia ser descrita, grosso modo, da seguinte maneira: com o crescente desenvolvimento da ciência desde o século XVII, o homem avançava cada vez mais no domínio da natureza - avanço consubstanciado na transformação dos materiais em produtos e na domesticação parcial dos elementos, tudo justificado como sendo em prol do constante aumento da qualidade de vida. $O$ pensamento moderno que surge em torno da metade do século XIX, é a afirmação, quase uma jactância, da ciência como protagonista desse processo, afastando qualquer dúvida ou incerteza sobre os limites do progresso humano e asseverando a perfeição do caminho que a sociedade daquele tempo trilhava.

Pode-se ver o moderno também como a vitória definitiva da ordem burguesa sobre a tradicional, ou o que restava da antiga sociedade dominada pela nobreza e pelo clero. Por isso, 0 frenesi pela mudança e o desprezo pelo antigo e pela tradição. Sem dúvida, isso era uma visão de mundo e as pessoas se reconheciam nela. Tinham a percepção de fazer parte de um processo, como pequenos motores, que operando em conjunto, se não em simultâneo, em etapas ordenadas, moviam um gigantesco mecanismo, a sociedade, na direção segura de um venturoso porvir. Os movimentos iniciados no final da década de 50, que se estenderam e ramificaram nos anos 60 do século passado, derrubaram de forma terminante essa cosmo visão. Mostraram que os governos não eram (e não são) confiáveis e que, antes de estarem a serviço do bem comum, estão a soldo da elite econômicofinanceira e dos interesses dos grandes grupos e corporações. Deixaram claro outrossim, que ao lado da face benévola da ciência existe outra, cruel, amiúde resvalando pela insensatez, capaz de aniquilar toda a vida do planeta e de uma série infindável de atentados menores, mas não menos terríveis, contra a condição humana. E, o pior, é que essas duas faces são inseparáveis, resultantes da subordinação da ciência à esfera do poder econômico. Não se trata de desvios a 
serem corrigidos, mas da conseqüência lógica de sua manipulação a partir dos interesses dominantes.

Além de toda a agitação cultural e política, a conjuntura igualmente não andava bem no aspecto econômico. Depois de um longo período de crescimento acelerado, que perdurava desde o pós-guerra, as economias dos principais países entraram em crise, abertamente no lado ocidental e velada, porém irreversivelmente, nos países ditos comunistas. A partir de 1973, após o aumento dos preços do petróleo decretado pela Organização dos Países Exportadores de Petróleo (OPEP), a economia mundial (com exceção de alguns países, como o Japão) ficou estagnada, patinando em um movimento que ficou conhecido como stop and go. As políticas keynesianas, inspiradas no aumentos dos gastos públicos para reativar os negócios, não mais surtiam efeito, só conseguiam provocar inflação pelos imensos déficits que abriam nas contas do governo, agravando ainda mais as suas já combalidas finanças. Com isso várias noções que pareciam consolidadas foram postas na berlinda. Uma das mais importantes a entrar em colapso foi a da promoção do desenvolvimento econômico, via planejamento ou políticas setoriais, amparado por generosos financiamentos públicos. A outra, com conseqüências talvez até piores para a população, foi o enfraquecimento acentuado dos compromissos do poder público com a construção e sustentação pelo estado do bem-estar social. O moderno não mais se sustentava, suas contradições estavam escancaradas, desmanchando por completo qualquer possibilidade de manutenção de sua coerência interna. A roda da história havia girado. Rei morto, rei posto.

\section{O P Ó S-M O D E R N O}

O sucedâneo do moderno, que convencionou-se chamar de pós-moderno, não só mantém uma das principais características do primeiro, a mudança incessante, como a exaspera aproximando-a do paroxismo. Mas agora, esse conjunto de transformações já não faz parte de um todo, não se encaixa em nenhum sentido específico. Pelo contrário, essas transformações apontam para diversas direções, não raro, divergentes. Já não existe nenhuma visão de mundo à qual se possa atribuir a capacidade de unir em torno de si toda uma sociedade. $\mathrm{Na}$ ausência dela, cada indivíduo constrói seu próprio entendimento de mundo, sem a preocupação de vincular-se ao modo pelo qual as demais pessoas vêem o mesmo mundo, o que dá origem a um processo de ruptura e fragmentação cada vez mais acelerado, parecendo não ter fim.

O horror ao totalitarismo, especialmente aos regimes ditatoriais que existiam nos países socialistas e do terceiro mundo, é a fonte de inspiração para um movimento de recuperação das vozes individuais, que transborda em intenso repúdio às visões unificadoras de mundo. Não é de outro lugar que Foucault extrai a idéia de que, na verdade, o poder não se encontra no aparelho de Estado, mas sim no que se poderia chamar das instituições mais elementares - na escola, nas empresas e escritórios, nos hospitais e nos lares. Para ele esses são espaços onde a relação de poder é instalada sem qualquer ligação com a dominação de classe. Sua proposta era de que o combate ao capitalismo saísse das grandes correntes e partidos políticos, para concentrar-se nesses microcosmos. Em última instância, pregava uma resistência localizada à repressão nessas instituições ou, em outros termos, a total pulverização da ação política. Porém, não há qualquer indicação das formas pelas quais a luta proposta poderia ser conduzida e o projeto de Foucault de contestação ao capitalismo nunca ultrapassou a dimensão teórica. De modo análogo, embora reconhecendo a autenticidade das vozes das minorias por tanto tempo sufocadas, o pós-moderno também fracassa em Ihes dar espaços concretos de poder. Elas falam no vazio. 
Na prática, o projeto de vida das pessoas desloca-se do social ou do grupo para o plano preponderante do individual. O eu torna-se o centro prioritário de interesse, fazendo do egocentrismo a marca do pós-moderno. A conseqüência mais visível é a busca sôfrega do prazer, a procura do bem-estar, este, confundido com a aquisição desenfreada de bens, com as viagens para fugir do tédio, mas onde se evita o auto-conhecimento, com o escapar-se das contrariedades, grandes ou não, mesmo implicando na ruptura de laços familiares, de amizade ou qualquer outro. Em suma, o que importa é a felicidade, tomada pela diversão na maior quantidade e pelo tempo mais longo possível, na maioria das vezes confundindo-se com o consumo, para o qual serão direcionados todos os recursos disponíveis. O termo que talvez seja o mais adequado para definir esse comportamento é o hedonismo, transplantado da cultura grega, mas devidamente adaptado para os dias que correm. As pessoas desistiram de tentar entender e modificar o mundo: querem apenas aproveitá-lo (curti-lo) da melhor maneira possível, de fato alheando-se de tudo e todos e merguIhando num estado de quase semicons-ciência. Como a existência é vista como devendo ser permanentemente alegre, deve-se fugir ou esquecer de suas demais faces. A vida, inevitavelmente, fica de través. $O$ ego passa a ocupar o centro do universo e este último serve ao primeiro, é explorado a partir de sua utilidade na satisfação dos desejos do indivíduo. Deixa-se de lado qualquer idéia de simbiose entre a pessoa e o meio que a cerca, e estabelece-se (ou busca-se estabelecer) uma relação do tipo colonial, onde o indivíduo (a matriz) procura fruir de todo o resto (o mundo) para proveito próprio, de modo imediato, descartável e, amiúde, predatório.

A busca para si do máximo deleite, faz com que cada um construa uma visão de mundo particular,; esta, embora possa ter pontos em comum com outras, não se agrega a elas, pois se encerra e se esgota em si mesma. Não existem mais, portanto, as grandes mundividências capazes de costurar elos de união entre as grandes massas. As visões de mundo compartilhadas são progressivamente genéricas, baseando-se em conceitos bastante esmaecidos pela globalização, como o de nação ou, devido às grandes correntes de imigração dos países pobres para os ricos, como o de etnia. Aliás, esses conceitos assentam a força que lhes resta, mais por se apresentarem como símbolos da reação, baluartes contrários aos movimentos globalizantes, do que propriamente pela força intrínseca que ainda possam ter na sociedade. $\mathrm{Na}$ dispersão do pós-modernismo, o que se comparte, como norma, são os pequenos e pobres universos das tribos coevas, que se juntam e desfazem-se ao sabor dos corpos de pensamentos gerados nos lugares e/ou pelas atividades da moda. Não há passado ou futuro, o que importa é o agora. Consuma e esqueça. Viva e aproveite o que puder e com a máxima intensidade possível. Carpe diem.

Em suma, o sujeito pós-moderno abre mão de construir caminhos em comum, dos grandes projetos cultivados na modernidade, da condução de seu destino. Despreza a utopia para viver o presente como se este fosse também o passado e o futuro, contemplando-o embasbacado, abandonando a Razão e revivendo mitologias. Depois de longa trajetória, da qual apenas na modernidade se logrou escapar das mãos de Deus, a sociedade humana corre agora, pelas artes da imagística pós-moderna, o risco de quedar-se aos pés do mercado.

As implicações dessas posturas no âmbito coletivo são imensas. O projeto modernista atacava e procurava equacionar as grandes questões, algumas vezes com êxito ou relativo sucesso, em outras ocasiões fracassando rotundamente. Por esse aspecto, o modernismo era infinitamente melhor que o laisser-faire que se observa no pós-modernismo, o "lavar as mãos" dos responsáveis pela condução das nações, enquanto problemas como o desemprego e a 
pobreza se acumulam e ganham dimensões alarmantes. Despreza-se qualquer planejamento, pela sua associação anterior com o centralismo e o autoritarismo, mas, ao invés de investir no aperfeiçoamento da idéia de preparar adrede a ação, incluindo nesse arranjo o diálogo e o convencimento, o pós-modernismo alimenta a crença em que o crescimento dos negócios se encarregará, sozinho, de sanar as cousas. A aposta nesse ente anárquico chamado mercado é arriscada, para não dizer insensata, em termos do aumento e do aguçamento das contradições e desigualdades, que vão sendo geradas no cerne da sociedade. Na verdade, existe sim, senão um planejamento, uma série de medidas e políticas por parte dos países líderes, que perfazem uma estratégia e se encaixam em uma lógica de favorecimento do ambiente econômico para o capital, em detrimento do trabalho, da natureza, da qualidade de vida, de qualquer coisa que se interponha no caminho do lucro. Implementadas, até com certo escárnio pelos vencedores do conflito leste-oeste, ações fundadas por exemplo no Consenso de Washington criam enormes instabilidades e perdas no número de empregos e na renda dos trabalhadores. Deixa-se de lado a perspectiva do bem estar social, em favor de uma "eficiência" e de uma "racionalidade" econômica de tal gênero, que simplesmente desdenha o que acontece às pessoas. Quase não existem mais tentativas de melhorar o mundo ou corrigir injustiças. As utopias desapareceram ou caíram no ridículo. A máxima que ganha força nos nossos dias é cada um com seus problemas.

De imediato, o pós-modernismo presta inestimáveis serviços à acumulação de capital, ao evitar o confronto e o questionamento da realidade socioeconômica. Com isso, deixa o campo livre para a chamada flexibilização do mercado de trabalho que, trocada em miúdos, significa a informalização do trabalho assalariado, ou ainda, a compressão dos salários e o aumento da jornada de trabalho. Não é pouco, pois se trata de uma volta à extração absoluta da mais-valia. É o caso de se sentir saudades das propostas do fordismo (que, à luz dos métodos atuais, parece incrivelmente civilizado) e da sua preocupação com a racionalização dos processos de trabalho, com vistas ao aumento da mais-valia relativa. Como, em paralelo, havia a preocupação de constituir um mercado de massas para o escoamento dos produtos, o fordismo concedia, para esse fim, ganhos reais aos salários, isto é, repartia entre capital e trabalho o incremento da mais-valia relativa. $\mathrm{O}$ papel dos aumentos reais da remuneração dos trabalhadores, na constituição de um mercado de massas era eliminado. Tudo vira ao reverso com a substituição que ocorre nesse processo: elevava-se o poder aquisitivo da população, pela redução de preços dos produtos; mas esta redução do preço era possibilitada, justamente, pela queda dos salários e dos encargos trabalhistas. No entanto, não é fácil manter dessa forma o dinamismo do mercado. Destarte, são necessárias algumas linhas auxiliares para alavancar o consumo, como a aceleração do giro dos produtos propiciada pelas modas fugazes e a sucessiva diminuição do tempo de vida útil das mercadorias. Sem dúvida, pode-se tomar alguns desses sinais como prenúncios de uma provável volta ao modo de exploração selvagem dos trabalhadores, que durante tanto tempo caracterizou o capitalismo. É irônico lembrar-se que, ainda no final da década passada, Domenico de Masi vaticinava o aumento do tempo livre das pessoas, dada a diminuição da jornada de trabalho que as novas tecnologias possibilitariam, e preocupava-se com o desafio de como ocupar os indivíduos durante esse ócio estendido.

\section{COSMOSE CONHECIMENTO}

Esse indivíduo descentrado, para o qual grande parte dos laços desapareceram, que só deseja viver na felicidade advinda da auto-fruição, desconectado das preocupações sociais, ensimesmado, como vai ele interagir com a 
montanha de informações que os meios de comunicação de massa não se cansam de despejar sobre ele? Terá, certamente, que filtrar essa imensa quantidade de informações e ele o fará pelos critérios mais rasos, pelo juízo moral de perspectiva mais estreita, o do indivíduo. Selecionará inicialmente, aquelas informações que possam lhe trazer vantagens pecuniárias ou pessoais que, em última instância aumentem seu poder de usufruir o mundo. É como se a consciência de ser um membro efêmero da espécie fosse tão pesada a ponto de ser insuportável. É imperioso afastar-se das responsabilidades coletivas, mas é impossível livrar-se do sentimento de culpa. Para aliviar essa dor, enterrar o mal estar, nublar essa consciência, os escapes são o consumo e o prazer. Contudo, esse comportamento não resolve a situação, é mais droga que remédio: seus efeitos, tal como os das drogas, dissipam-se em pouco tempo e para continuar produzindo as mesmas sensações precisam ser obtidos e sorvidos em escalas cada vez maiores.

Por esse caminho, também o sentido da informação perde-se na sua essência. O que se busca na informação é o seu significado mais superficial, aquilo que tem serventia para o cotidiano e o imediato, que impulsiona a ascensão social e os projetos de vida que começam e terminam na pessoa. A perda da identidade coletiva e dos compromissos a ela associados, faz com que o uso da informação não se preste a erigir uma compreensão do mundo, cada vez mais ampla e sólida, que harmonize a inserção individual na sociedade e na natureza; ao invés, a informação é examinada de maneira superficial, para consumir-se instantaneamente e, logo a seguir, descartada. Haure-se apenas algumas gotas de um grande oceano. A maior quantidade disponível de informações, apenas induz a aumentar a velocidade desse modo de manuseio, dada a ânsia do indivíduo de inteirar-se e aproveitar-se de tudo o que é oferecido pela mídia. Em conseqüência, ao deixar-se de lado uma parte substancial de sua acepção, a informação é empobrecida.

Urge, portanto, buscar um novo entendimento de mundo. Porém como fazer isso? Certamente, não mais com as pretensões de univocidade e tentativas de imposição de unanimidade do moderno, mas de uma maneira que acomode as diferenças e cultive a pluralidade. Seria possível, ao invés de explicitar uma cosmo visão a partir de uma concepção dominante, reunir várias cosmo visões, correspondentes a cada uma das diversas possibilidades de compreensão do universo, de forma a comporem um multiverso ${ }^{2}$, onde todas essas partes possam fazer sentido? Todas deveriam ser entendidas como modos de abordagem daquilo que nos cerca, uma realidade tão complexa para a nossa capacidade de entendimento, que só a conseguimos representar parcialmente, de modo incompleto e distorcido, cada qual de acordo com as lentes fornecidas por sua mente. Se assim for, talvez cada uma delas pudesse ganhar vida própria e formar universos específicos. Daí a analogia com o multiverso, ou seja, um mundo composto por vários universos, que embora pareçam existir de forma autônoma fazem parte de um todo maior e estão, de algum jeito, interligados.

No entanto, mesmo assim, haveria a necessidade de se valorar as diversas concepções de mundo, de acordo com determinados critérios. Caso contrário, se todas tivessem o mesmo valor, nenhuma teria valor. Pois bem, como eleger tais critérios? Poderiam ser mais valoradas, por exemplo, as visões de mundo que contemplassem a justiça e o bem

\footnotetext{
${ }^{2}$ Segundo Marcelo Gleiser em seu artigo, O Universo de Babel, no caderno Mais da Folha de São Paulo de 2/2/2003, o termo foi inventado por cosmólogos para diferenciar o universo em que vivemos de todos os outros possíveis. Segundo Marcelo Gleiser em seu artigo, o Universo de Babel, no caderno Mais da Folha de São Paulo de 2/2/2003, o temo foi inventado por cosmólogos para diferenciar o universo em que vivemos de todos os outros possíveis.
} 
estar social. Por certo são bons critérios, mas seriam suficientes? Dada a miríade de interesses humanos, obviamente inúmeros outros poderiam ser agregados a esses dois itens iniciais, formando uma imensa lista de pontos, pelos quais cada mundividência poderia ser apreciada. Por fim, seria preciso elencar todos esses critérios e colocá-los, de algum modo, em uma escala crescente ou decrescente de valores, de tal jeito que obtivesse a aceitação da maioria dos indivíduos que compõem a sociedade. Tal empreitada, se viável, permitiria recompor o que hoje está esfacelado, confuso, caótico, transformando a "desordem [...] em todo orgânico, num cosmos", para retomar a epígrafe de Bruno Latour. Todavia, reconheça-se que fórmulas ou caminhos para essa construção simplesmente não estão disponíveis no momento, se é que estarão algum dia (LATOUR, 2000ab).

\section{Ética}

Em outro espectro existem propostas que se pretendem menos radicais e que vêem, ao lado da falência atual de valores, a reativação de uma nova moral, como aspiração coletiva. Essa é a tese de Lipovetsky, quem crê que, nos nossos tempos, assiste-se à instalação de um novo tipo de ética. Seu modelo não se funda na moral religiosa, que pregava a renúncia a si próprio e dedicação absoluta aos deveres para com Deus. Outrossim, não se inspira na moral laica nascida com as idéias do iluminismo, que celebrava os deveres do homem e do cidadão sob normas rígidas e transferia as obrigações em relação a Deus para a esfera humana. As características da moral moderna, que prevaleceu de meados do século XVIII até mais ou menos a primeira metade do século $X X$, estabelecia deveres incondicionais do indivíduo para com ele próprio, com os outros e com a coletividade. Os sacrifícios não deviam mais ser dirigidos a Deus e sim ao "altar da família, da pátria ou da história" (LIPOVETSKI, 1994, p. 16).
Na segunda metade do século passado, teria emergido no mundo ocidental uma nova ética que, negando os deveres e obrigações, prega a satisfação imediata dos desejos e o desfrute dos bens materiais, exalta o ego e os prazeres proporcionados pela posse. Com esses apelos, formou-se o que Lipovetsky denomina de sociedade pós-moralista. Todavia, embora dominante, essa moral não fez desaparecer por completo as anteriores. A coexistência entre diferentes regras de conduta fica clara, quando surgem movimentos que tentam conter, por exemplo, a corrupção e o descaso e combater o trabalho escravo, as drogas e as agressões ao meio ambiente.

Ao estímulo do processo de exclusão social dentro do mecanismo de reprodução ampliada do capital, que resulta naturalmente da aplicação das políticas econômicas neoliberais alia-se, para expandir as mazelas do mundo, o enfraquecimento dos meios tradicionais de controle social: igreja, família, escola, sindicatos. Porém, Lipovetsky não enxerga aí o prelúdio do fim da sociedade, pelo mergulho na confusão e na violência e, principalmente, pela indiferença das pessoas em relação ao que sucede com as outras. Ele acha que, ao declínio generalizado das virtudes, contrapõe-se um processo de reorganização ética, que emerge do próprio individualismo. O embate entre essas duas correntes estabelece uma nova dialética que possibilita "pensar a era pós-moralista como um "caos organizador" (LIPOVETSKI, 1994, p. 20). Sob a égide do individualismo e em torno desse conflito, vai ser jogado o futuro da democracia ocidental. A sobrevivência desta dependerá da capacidade de fazer com que o individualismo irresponsável recue e, em seu lugar, assome o individualismo responsável, com uma redefinição correspondente das condições políticas, sociais e econômicas que hoje predominam.

Na seqüência, o autor relativiza as esperanças depositadas na ética tradicional como a força capaz de atacar com sucesso a miséria, 
os danos contra o meio ambiente, o racismo e a violência só para citar alguns dentre os inúmeros males que afligem a humanidade, quando constata que, na maioria das vezes, as ações dos indivíduos, empresas e governos contradizem os elevados princípios anunciados em seus discursos oficiais, ou seja, descobre que o discurso é diferente da prática, o propósito não coincide com o gesto. Termina agarrando-se ao que chama de "[...] éticas inteligentes e aplicadas, menos preocupadas com intenções puras do que com resultados benéficos para o homem, menos idealistas que reformistas, menos adeptas do absoluto que de mudanças realistas, menos injuntivas que responsabilizadoras" (LIPOVETSKI, 1994, p. 23). Acredita que esse tipo de ética, apoiada na razão, por sua vez vista como algo inerente à espécie, efetuará o resgate dos grandes valores da humanidade. O homem trilharia a rota do progresso no seu sentido amplo, isto é, não só material, ainda que sob "as circunstâncias, com os interesses e as exigências da eficácia." (LIPOVETSKI, 1994, p. 25). Em seu juízo, esse gênero de ética, embora fraco no plano individual, é forte no plano do coletivo e no das organizações públicas e privadas.

É o caso de se perguntar porque as coisas deveriam ocorrer dessa forma? É possível considerar a ética como algo que paira sobre a sociedade, descolada dos atos das pessoas no dia-a-dia, que formam as consciências e as ideologias? Uma ética desse tipo é compatível com a ética do capitalismo, na qual a busca do lucro quase não tem limites e prevalece sobre qualquer outro interesse? Há na natureza humana noções conatas como a sensatez e a justiça social, capazes de produzirem alguma coisa semelhante ao "individualismo responsável"?

A trajetória recente do capitalismo pode dar certas pistas. Em toda a sua história esse modo de produção nunca foi tão progressista como no século passado, não por mero acaso ou por haver alcançado uma etapa natural do seu desenvolvimento, mas porque a necessidade de ser mais justo socialmente sobrevinha da política. Era preciso negociar com os trabalhadores e seus sindicatos, dividir com eles os ganhos de produtividade (a mais-valia relativa), dar aumentos reais para os salários, para instituir um modus vivendi que possibilitasse manter o sistema capitalista em operação e afastar o espectro do socialismo. Unindo o útil ao agradável, o fato dos trabalhadores ganharem mais significava que também podiam consumir mais, o que acabou por viabilizar a realização da produção industrial em massa no mercado de consumo do mesmo nome. Mais mercado, mais lucro. O capitalismo é impressionantemente criativo.

Com a ruína dos regimes autodenominados socialistas, o capital ficou sem nenhum oponente político de peso e sentiu-se livre, novamente, para retomar antigas práticas. Ressuscitou hábitos que se afigurava estarem definitivamente sepultados no passado, como a extração da mais-valia absoluta, da qual os melhores exemplos são o aumento da jornada e a informalização crescente no mercado de trabalho. Assim trabalha-se mais para ganhar o mesmo ou menos. Em nome da eficiência, medida pelos menores custos (ou lucros maiores), promove-se o crescimento da miséria. Desaparecem os postos de trabalho e a renda correspondente, devido à automação desenfreada; tornam-se precários os vínculos trabalhistas, aguça-se a luta pela sobrevivência, enquanto a contingência passa a ser a marca da sociedade. Implanta-se o que Harvey, eufemisticamente, chama de modo de acumulação flexível.

Qual ética pode emergir desse quadro? Provavelmente uma ética maleável e amorfa o suficiente para tolerar tais desvios. A ética real é moldada de acordo com os comportamentos e consensos formados na sociedade e não o contrário. A sensatez, o senso de justiça, o desprendimento e outros valores nobres não são, 
exatamente, qualidades inerentes à sociedade humana, como demonstram tanto o apogeu, como a queda de várias civilizações que antecederam a atual. Os movimentos que Lipotevsky vê como sinais dos freios que a sociedade procura impor ao individualismo irresponsável, podem ser encarados também como os últimos espasmos do dever na consciência coletiva, os últimos resquícios do moderno antes do mergulho profundo no vazio do cada um por si.

\section{NOVAMENTE A CIÊNCIA COMO A I T E R N A T V A}

As melhores e mais instigantes proposições são apresentadas por Morin e Boaventura Santos. Ambos acreditam que já está em curso há algum tempo, talvez em vias de consumarse, um processo de transformação radical dos princípios que nortearam até aqui a ciência. Morin aponta que a ciência clássica apoiava-se em três pilares: 1) a ordem - baseada na idéia de que os fenômenos do universo são guiados por algum tipo de determinismo, que tanto pode ser divino como absoluto; 2) a separabilidade - segundo a máxima de Descartes, para analisar um problema complicado é preciso dividi-lo em partes e trabalhar com cada uma delas em alguma seqüência. Assim nasce e desenvolve-se, até quase a exasperação, a especialização científica. Para evitar qualquer perturbação na análise, separa-se também o sujeito do objeto; 3) lógica - por meio da indução, da dedução e ainda dos preceitos aristotélicos, formulam-se as leis gerais, os grandes sistemas de conhecimento científico.

Apesar dos resultados brilhantes que alcança, o paradigma da ciência clássica baseado na certeza absoluta, começa a entrar em crise com as descobertas da física quântica e da termodinâmica, que introduzem a desordem no antes perfeito universo newtoniano. Algumas décadas depois surgem as ciências ditas sistêmicas, como as ligadas ao meio ambiente, que passam a considerar as articulações e as interações entre as diversas partes, inclusive com os seres humanos, isto é, com o próprio sujeito. Outro elemento perturbador é a dificuldade de caracterizar algumas coisas de modo claro, por exemplo, determinar se algumas partículas são ondas ou corpúsculos. Eis a separabilidade agora em xeque. No tocante à lógica, a polêmica vem da constatação da existência de vários casos em que as regras construídas a partir da indução e da dedução, não são certezas absolutas, apenas fortes possibilidades. Por todas essas portas penetrou o vírus da dúvida, letal para o paradigma da ciência clássica.

O paradigma emergente é o do pensamento complexo que se assenta em três linhas fundamentais: 1) a complexidade deve ser considerada no seu todo, abarcando sua contextura, sem separar ou isolar suas partes; 2) a incerteza passará a ser incorporada à ciência. Para lidar com ela, serão necessárias estratégias como o uso das ferramentas da estatística e o auxílio do computador, com sua enorme capacidade de cálculo; e, por fim, 3) a racionalização migrará do modo fechado para o aberto. No seu modo fechado, privilegia-se a consistência e a coerência dos sistemas e eliminam-se os fatores de perturbação. Por causa desse procedimento, esses sistemas entram em colapso, quando ocorrem eventos inesperados. No modo aberto, colocar-se-á a lógica a serviço da razão e será abandonada de vez a idéia dos modelos perfeitos de representação dos fenômenos.

O cerne da teoria de Morin é a colocação e a inclusão da desordem na ordem das coisas, isto é, o reconhecimento da existência eterna dessas duas forças no universo, cujo encontro gera a criação e a organização. Isoladamente a ordem é plana e estéril e a desordem sozinha é a inviabilidade do cosmos. O mundo nasceu do caos, no sentido dado pelos gregos: de forças colossais e violentas que contêm, ao mesmo tempo, a ordem e a desordem. Estas duas forças, 
combinadas em diversas proporções, dão origem às galáxias e estrelas e também à barbárie e à civilização. A dialética de Hegel representa esse embate incessante que ocorre no mundo, por meio do choque entre a contradição e a conciliação resumida na célebre expressão: tese versus antítese, igual à síntese. O conhecimento absoluto que deriva do determinismo não tem mais lugar na ciência. Em qualquer sistema deve-se deixar espaço para a imprevisibilidade e a desordem. O conhecimento produzido por esse novo paradigma deverá estar baseado na religação das partes, na conjunção e implicação mútua. A ciência deve passar a considerar o todo. Isso implica mudar o ensino e transformar radicalmente o modo de pensar atual, adotar 0 pensamento complexo.

Há muitas semelhanças entre o que diz Morin e o diagnóstico sobre a mesma questão realizado por Boaventura Santos. Este último também vê o paradigma atual da ciência, em crise, por motivos análogos aos levantados pelo primeiro. Na exposição de Boaventura, a ciência moderna se impõe pela luta contra todas as formas de dogmatismo e autoridade e se estabelece por duas distinções fundamentais, a distinção entre o conhecimento científico e o do senso comum, e a distinção que opõe natureza e ser humano. A partir de seu sucesso, a ciência constrói um modelo totalitário, que se nega a validar qualquer outro tipo de conhecimento que não siga seus princípios e métodos. O grande instrumento da ciência é a matemática, que fornece as normas para a análise, a lógica da investigação e a estrutura para a representação da matéria. Assim, conhecer é quantificar e quanto mais apuradas são as medidas, maior é o rigor científico. Sua grande estratégia é a redução da complexidade. Constatada a impossibilidade da mente humana abarcar o mundo, a saída é dividi-lo e estudá-lo separadamente em cada uma de suas múltiplas partes e depois procurar determinar as relações entre elas. O conhecimento gerado como base nesses procedimentos, é causal, apropriado à formulação de leis que permitem prever o comportamento dos fenômenos, a partir das regularidades observadas no passado. Tal saber é bastante eficaz quando se trata de explicar como as coisas funcionam; mas é inoperante para compreender a finalidade delas. A ordem e a estabilidade do mundo são seus pressupostos essenciais.

Boaventura Santos vê a época atual como a fase de transição do paradigma da ciência moderna para o da ciência pós-moderna. Observa inicialmente que a crise do paradigma dominante é resultado dos seus próprios avanços. Ao aprofundar o conhecimento sobre o real, a ciência moderna percebe que seus pés são de barro. Essa fragilidade vai se evidenciando por uma série de descobertas, que abrem espaço para o surgimento de novas condições teóricas e fazem a crise vir à tona. O primeiro impacto decorre da demonstração de Einstein que tempo e espaço não são absolutos. Portanto, as leis da ciência têm validade apenas local, submetidas a determinadas configurações do espaço/tempo e sua extrapolação para todo o universo é arbitrária, ou seja, incerta. $\mathrm{O}$ segundo abalo advém da mecânica quântica, quando Heisenberg e Bohr postulam que, no mundo das partículas, não é possível observar ou medir um objeto sem interferir nele. Por decurso, percebese que o homem não conhece o real tal como ele é, mas apenas o real alterado por sua interferência. Se o rigor do conhecimento é limitado, os resultados nunca serão exatos e as leis científicas serão apenas probabilísticas. $\mathrm{O}$ próprio valor da matemática enquanto instrumento de medida e, portanto, da garantia do rigor científico é posto sob suspeita com os teoremas de Gödel. Estes demonstram a impossibilidade, em certos casos, de encontrar dentro de um sistema formal provas de sua consistência, mesmo seguindo ao pé da letra todos os preceitos da lógica matemática. O rigor da matemática, assim sendo, também não é absoluto, mas unicamente mais uma espécie 
de pontualidade, circunscrição, ao lado de outras formas alternativas.

Por fim, o quarto solavanco vem da teoria das estruturas dissipativas, segundo a qual em sistemas abertos, onde flutuações de energia desencadeiam reações que os levam para situações críticas de estabilidade, a ordem é restabelecida mediante a passagem para um novo estado de equilíbrio, de menor entropia. Ao ir para o novo estado o sistema não pode mais retornar para o anterior, a mudança é irreversível. Isso significa que as coisas não se repetem e a evolução é produto da história. Toda a concepção da matéria e natureza herdada da física clássica é posta de cabeça para baixo. "Em vez da eternidade a história; em vez do determinismo a imprevisibilidade; em vez do mecanicismo a interpenetração, a espontaneidade e a auto-organização; em vez da reversibilidade a irreversibilidade e a evolução; em vez da ordem a desordem; em vez da necessidade a criatividade e 0 acidente" (SANTOS, 1997, p.28).

O paradigma da ciência pós-moderna, especula Boaventura Santos, deve ser o "de um conhecimento prudente para uma vida decente" (SANTOS, 1997, p.37). Ademais, com os recentes avanços da física e da biologia estão postas em causa as distinções entre orgânico e inorgânico, seres vivos e matéria inerte, humanos e não humanos. Por analogia deixa de haver sentido também na separação entre ciências naturais e ciências sociais. O novo modelo de investigação científica marcará o fim do conhecimento dualista e essa superação ocorrerá sob a égide das ciências sociais, já que são os modelos explicativos destas que estão sendo incorporados pelas ciências naturais. Os conceitos absorvidos pelas ciências naturais atribuem à natureza um comportamento humano, ou dito de outra forma, admite-se a indistinção entre o comportamento humano e o da natureza. Conseqüentemente, as ciências sociais também serão profundamente transformadas. A síntese dessa metamorfose pode ser expressa na colocação da natureza no centro da pessoa (o autor e o sujeito do mundo), ao revés do que fazem as disciplinas de humanidades tradicionais.

A segunda característica do novo paradigma científico é que ele deve avançar em direção ao conhecimento total, abandonando a especialização, a divisão por disciplinas. Para ser total esse conhecimento terá também de ser local. Ele se constituirá em torno de temas que serão adaptados por determinados grupos sociais, para por em prática projetos específicos como, por exemplo, melhorar as condições de saneamento de uma cidade. Esses temas funcionarão como dutos, por intermédio dos quais os diferentes conhecimentos irão uns ao encontro dos outros, formando um saber ampliado, multidisciplinar e que cresceria constantemente, como as raízes e os galhos de uma árvore entrelaçando-se com as demais na floresta.

A separação entre sujeito e objeto promovida pela ciência moderna estaria com os dias contados. O sujeito deverá regressar misturandose com o objeto. Este último, por sua vez, passará a ser encarado como uma continuação do sujeito, de tal modo que o conhecimento científico do objeto será também auto-conhecimento. Dessa forma, reconhecer-se-ia definitivamente que sistemas de crenças, juízos de valor, pressupostos metafísicos são partes integrantes da explicação científica. Por isso mesmo, a ciência moderna não é a única via de explicação da realidade, aponta corretamente Boaventura Santos, para em seguida cometer um exagero colocando-a em pé de igualdade com as explicações alternativas da religião e da astrologia. O legado de conhecimento funcional deixado pela ciência moderna já não basta, é necessário "um conhecimento compreensivo e íntimo que não nos separe e antes nos una pessoalmente ao que estudamos" (SANTOS, 1997, p.53).

Pelo exposto anteriormente, Boaventura Santos conclui que o estatuto da racionalidade 
científica não é científico, é arbitrário. Privada do caráter científico, a ciência moderna perde o monopólio da capacidade de explicar o real. Aliás, a bem da verdade, deve-se recordar que a ciência moderna não busca explicar a natureza, apenas tenta controlá-la. Em conseqüência devem ser revalorizadas as demais formas de conhecimento. Assim, a ciência pós-moderna deverá se esforçar por restabelecer o diálogo e a interação com esses outros modos de conhecimento, notadamente o senso comum. Apesar de reconhecer que o senso comum é superficial, mistificador e conservador, Boaventura Santos acredita que ele tenha uma dimensão utópica e libertadora, que pode aflorar por meio de sua mistura com o conhecimento científico. Por essa via, se poderia chegar ao controle do desenvolvimento tecnológico sustando seus desvios e excessos e colocando-o dentro dos limites da sabedoria de vida e do bom senso. "É este que assinala os marcos da prudência à nossa aventura científica. A prudência é a insegurança assumida e controlada" (SANTOS, 1997, p.57).

Os argumentos de Morin e Boaventura partem das razões que levam o atual modelo de investigação científica ao impasse e delineiam algumas faixas, pelas quais se poderia transitar em direção a um novo entendimento de mundo, apontando novamente para a ciência, porém uma outra ciência, muito diferente daquela que se conhece, porque estaria inserida dentro de um paradigma inteiramente novo. Ambos reconhecem na época presente uma fase de transição, um momento de passagem de um mundo que alcançou seus limites, para outro do qual mesmo os contornos ainda são pouco visíveis. Disso decorrem estes tempos conturbados, confusos e muitas vezes caóticos. O mérito dessas teorias é que elas não aventam soluções mágicas, não tiram ases das mangas, como a idéia que se vende da SI. Pelo contrário, apostam em processos históricos, em mudanças trazidas pelo esgotamento de padrões de pensamento, das formas de relação com a natureza e das mundividências que davam suporte a tudo isso.

Os dois autores anseiam pela construção de um saber totalizante, que promova uma visão abrangente e integrada de mundo, recupere a ligação entre as partes e dê impulso à costura dos retalhos, em que a especialização em disciplinas da ciência moderna fatiou o conhecimento. Almejam portanto por teorias totalizantes, por cosmovisões que indiquem o lugar do homem no universo, que estabeleçam uma relação harmoniosa entre sujeito e objeto, não os colocando em lados opostos. Quando alertam para a necessidade de incorporar a desordem na ordem das coisas, na verdade estão propondo uma nova ordem, na qual a desordem esteja contida, como parte integrante dela. Estão dizendo que o estado natural do mundo é o estado de mudança, da contínua transformação no rumo de algo ignoto (ou que ainda se ignora), em oposição à estabilidade e à repetição subjacentes ao determinismo.

A principal diferença entre Morin e Boaventura Santos está nas características que cada um imagina para o novo paradigma. Enquanto o primeiro propõe a complexificação do pensamento, por meio de mudanças no ensino e no próprio modo de pensar, o segundo joga as fichas no amálgama entre o senso comum e a ciência, com o senso comum policiando o comportamento da ciência, contendo seus desvios. Dito de outro modo, Boaventura opta pela vulgarização da ciência, por uma maneira de torná-la clara e inteligível, se não a todos, pelo menos para a maioria dos cidadãos, sem depender de avanços nos métodos de ensino ou no nível da educação formal. No entanto, a tradução da ciência para o senso comum, se é factível, não é uma tarefa fácil.. Um bom e expressivo exemplo da dificuldade desse tipo de conversão, pode ser encontrado na tentativa de síntese do texto de Boaventura. realizada neste presente ensaio. 
CONSIDERAÇÕES FINAIS

Os limites da compreensão humana do universo são dados pela capacidade mental da espécie, pelo fato do alcance do pensamento não suportar estruturas demasiado complexas, como as que existem na realidade. O universo, desde o seu início caminha para um grau de complexidade crescente, partindo da sopa de partículas primordial até chegar aos aglomerados de galáxias. Na mesma direção vai a sociedade humana. Assim, como simplificar uma realidade que vai se tornando cada vez mais complexa? Na há como e o próprio Boaventura ilustra essa impossibilidade com a teoria dos sistemas abertos, os quais, uma vez perturbados somente reencontram seu equilíbrio em outro estado, jamais retornando ao estágio anterior. Não há volta ao passado, o que existe é a história. Resgatar o senso comum não deixa de ser uma volta ao passado, um saudosismo. Se a ciência surgiu em oposição ao senso comum, sustevese por causa dos defeitos deste último, como as crendices que puderam ser desmentidas

\section{REF ER Ê NCIAS}

GASPARI, E. A ditadura envergonhada. São Paulo: Companhia das Letras, 2002. p.234.

HABERMAS, J. O discurso filosófico da modernidade. 2.ed. Lisboa: Publicações Dom Quixote, 1998. p.36.

LAUTOR, B. Ciência em ação: como seguir cientistas e engenheiros sociedade afora. São Paulo: Unesp, 2000.

LAUTOR, B. Redes que a razão desconhece: laboratório, bibliotecas, coleções. In: Baratin, M.; Jacob, C. O poder das bibliotecas: a memória dos pelas novas práticas científicas, cujos resultados, de um modo ou de outro, foram preferidos pela sociedade. Destarte, imaginar o senso comum como sendo capaz de por freios aos excessos e transgressões da ciência, parece muito pouco plausível. O senso comum não teve forças para se contrapor a tais descaminhos, durante todo esses séculos da revolução científica. Por que seria capaz de fazê-lo agora? O senso comum também é produto das condições materiais e culturais de uma sociedade em determinado tempo. No seu âmago não existe um compromisso unívoco com a sensatez. Ele pode muito bem tornar-se insensato e a história é recheada de lições desse jaez, como no desencadeamento da repressão e perseguição ao judeus na Alemanha, e depois em quase toda a Europa, nos anos 30 e 40 do século passado. A era do senso comum foi a idade medieval e, todavia, foram tempos de escuridão intelectual, opressão, fome, guerra, superstição e peste. Não são exatamente credenciais para o papel que Boaventura Santos pretende Ihe atribuir.

livros no ocidente. Rio de Janeiro: UFRJ, 2000. p.21-44.

LIPOVETSKI, G. O crepúsculo do dever: a ética indolor dos novos tempos democráticos. Lisboa: Publicações Dom Quixote, 1994. p.16-25.

MOTOYAMA, S. Sobre o modelo lógico do desenvolvimento científico. São Paulo: Instituto de Geografia da Universidade de São Paulo, 1977. p.1-2. (Métodos em Questão,15).

SANTOS, B. S. Um discurso sobre as ciências. 9.ed. Porto: Edições Afrontamento, 1997. p.28-57. 